Pacific Journal of Mathematics

A NOTE ON DRAZIN INVERSES 


\title{
A NOTE ON DRAZIN INVERSES
}

\author{
CHEN F. King
}

\begin{abstract}
$D$ is the Drazin inverse of $T$ if $T D=D T, D=T D^{2}$, and $T^{k}=T^{k+1} D$ for some $k$.
\end{abstract}

In recent years, there has been a great deal of interest in generalized inverses of matrices ([2], [4], [5]) and many of the concepts can be formulated in Banach space. In particular, if $X$ is a Banach space and $B(X)$ denotes the algebra of bounded operators on $X$, then we make the following definitions:

Definition 1. An operator $S$ in $B(X)$ is called a generalized inverse of $T$ if $T S T=T$ and $S T S=S$.

Definition 2. An operator $T$ in $B(X)$ is called generalized Fredholm if both the range $R(T)$ and the null space $N(T)$ are closed complemented subspaces of $X$.

Let an operator $D$ in $B(X)$ be the Drazin inverse of $T$. Then $T^{k}=T^{k+1} D$ for some nonnegative integer $k$.

Definition 3. The smallest $k$ for which the latter is valid is called the index of $T$.

In fact, if an operator $T$ in $B(X)$ has a Drazin inverse then it has only one ([2], Theorem 1).

Remarks. (1) It is well known and easy to prove that $T$ is a generalized Fredholm operator if and only if it has a generalized inverse. Some properties of the operator thus defined are obtained in [1] but generally there remain unsatisfactory features. For example, in Banach space there is no obvious way of defining a unique generalized inverse and there is no useful relation between the spectrum of an operator and of any of its generalized inverse.

(2) The Drazin inverse was introduced in [2] in a very general context and avoids the two defects mentioned above. Note also that if the index is equal to 1 , then $D$ is a generalized inverse of $T$.

We will now proceed to obtain some properties of operators with a Drazin inverse including an exact characterization of such operators. In order to simplify the proof of Theorem 1, we prove the following lemma: 
Lemma 1. Let $T$ be an operator in $B(X)$. Then $T$ has a generalized inverse $S$ such that $T S=S T$ if and only if $X$ can be written $X=R(T) \oplus N(T)$.

Proof. Let $X=R(T) \oplus N(T)$ and let $P$ be the projection from $X$ onto $R(T)$ along $N(T)$. Let

$$
Q=T \mid R(T)
$$

then $N(Q)=(0)$ and $Q$ is bounded with closed range. Hence, $Q$ has a bounded inverse on $R(T)$. We define

$$
S=Q^{-1} P
$$

It is easy to see that $S$ is a commuting generalized inverse of $T$.

Conversely, if $T$ has a commuting generalized inverse $S$ then $T S$ is a projection from $X$ onto $R(T)$. Let

$$
X=R(T) \oplus X_{1},
$$

where $X_{1}=N(T S)$. For each $x \in X_{1}, T S x=0$ and

$$
T x=T S T x=T T S x=0 ;
$$

this implies $x \in N(T)$. On the other hand, for each $x \in N(T)$ then $T x=0$ and

$$
T S x=S T x=0
$$

this says $x \in X_{1}$. Consequently, $N(T)=X_{1}$.

In fact, $T S=S T$ implies $N(T)=N(S)$ and $R(T)=R(S) . \quad$ Thus,

$$
X=R(T) \oplus N(T)=R(S) \oplus N(S) .
$$

THEOREM 1. Suppose $T$ is an operator in $B(X)$ with generalized inverse $S$ such that $T S=S T$. Then the nonzero points in $\rho(T)$, the resolvent set of $T$ are precisely the reciprocals of the nonzero points in $\rho(S)$.

Proof. By Lemma 1, $X$ can be decomposed into

$$
X=R(T) \oplus N(T)
$$

Assume $\lambda \neq 0$ in $\rho(T)$ then 


$$
\begin{gathered}
(T-\lambda I)^{-1}(T-\lambda I)=I \\
T(T-\lambda I)^{-1}(T-\lambda I) S=T S,
\end{gathered}
$$

which yields

$$
-T(T-\lambda I)^{-1}\left(S-\frac{1}{\lambda} T S\right)=T S .
$$

Since $T S$ is the identity on $R(T)$, for each $x \in R(T)$,

$$
-\lambda T(T-\lambda I)^{-1}\left(S-\frac{1}{\lambda} I\right) x=x .
$$

This implies $(S-(1 / \lambda) I)$ has a bounded inverse on $R(T)$ for all $\lambda \neq 0$ in $\rho(T)$.

On the other hand, for each $x \in N(T)$

$$
\left(S-\frac{1}{\lambda} I\right) x=-\frac{1}{\lambda} x
$$

or

$$
-\lambda\left(S-\frac{1}{\lambda} I\right) x=x
$$

Thus $\left(S-\lambda^{-1} I\right)$ also has a bounded inverse on $N(T)$ for all $\lambda \neq 0$ in $\rho(T)$.

Because $\quad\left(S-\lambda^{-1} I\right) R(T)=\left(S-\lambda^{-1} I\right) R(S) \subseteq R(S)=R(T) \quad$ and $\left(S-\lambda^{-1} I\right) N(T)=\left(S-\lambda^{-1} I\right) N(S) \subseteq N(S)=N(T)$, so $1 / \lambda \in \rho(S)$.

The converse statement is established with $T$ replaced by $S$ and $S$ by $T$. The proof is complete.

REMARK. The commutativity condition in Theorem 1 is essential, for consider the shift operator $S:\left(x_{1}, x_{2}, x_{3}, \cdots\right)\left(0, x_{1}, x_{2}, \cdots\right)$ in $l^{2}$. Then $S S^{*} S=S$ and $S^{*} S S^{*}=S^{*}$ so that $S^{*}$ is a generalized inverse of $S$. But $\rho(S)=\rho\left(S^{*}\right)=\{\lambda:|\lambda|=1\}$.

TheORem 2. Let $T$ be an operator in $B(X)$ with Drazin inverse $D$ and index $k$. Then $D^{k}$ is a generalized inverse of $T^{k}$ and $D^{k}$ commutes with $T^{k}$.

Proof. Obviously $D^{k}$ and $T^{k}$ commute. Then

$$
D^{k} T^{k} D^{k}=D^{2 k} T^{k}=\left(D^{2} T\right)^{k}=D^{k}
$$


and

$$
\begin{aligned}
T^{k} D^{k} T^{k} & =T^{k+1} D^{k+1} T^{k} \\
& =T^{k+1}\left(D^{2} T\right) D^{k-1} T^{k-1} \\
& =T^{k+1} D^{k} T^{k-1} \\
& =\cdots \\
& =T^{k+1} D \\
& =T^{k} .
\end{aligned}
$$

Corollary. If $D$ is the Drazin inverse of $T$ with index $k$, then $X=R\left(T^{k}\right) \oplus N\left(T^{k}\right)$.

Theorem 3. If $T$ in $B(X)$ has a Drazin inverse $D$ and $\lambda$ is a nonzero point in $\rho(T)$, then $\lambda^{-1}$ belongs to $\rho(D)$.

Proof. $(T D)^{2}=T D T D=T D$, so $T D$ is a projection. It is easy to verify that $R(D)=R(T D)$ and $N(D)=N(T D)$. Hence $R(D)$ and $N(D)$ are closed complemented in $X$.

Since

$$
D\left(T^{2} D\right) D=T^{2} D^{3}=T D^{2}=D
$$

and

$$
\left(T^{2} D\right) D\left(T^{2} D\right)=T^{4} D^{3}=T^{3} D^{2}=T^{2} D
$$

this shows that $T^{2} D$ is a commuting generalized inverse of $D$. Then, by Lemma 1,

$$
X=R(D) \oplus N(D) .
$$

The rest of the proof is analogous to the first part of Theorem 1 since $T D$ is identity and zero on $R(D)$ and $N(D)$ respectively.

Recall the definition of ascent $a(T)$ and descent $d(T)$ for operator $T$ in $B(S)$ : an operator has finite ascent if the chain $N(T) \subseteq N\left(T^{2}\right) \subseteq$ $N\left(T^{3}\right) \subseteq \cdots$ becomes constant after a finite number of steps. The smallest integer $k$ such that $N\left(T^{k}\right)=N\left(T^{k+1}\right)$ is then defined to be $a(T)$. The descent is defined similary for the chain $R(T) \supseteq R\left(T^{2}\right) \supseteq$ $R\left(T^{3}\right) \supseteq \cdots . \quad$ If $T$ has finite ascent and descent, then they are equal ([6], Theorem 5.41-E). 
THEOREM 4. An operator $T$ in $B(X)$ has a Drazin inverse if and only if it has finite ascent and descent. In such a case, the index of $T$ is equal to the common value of $a(T)$ and $d(T)$.

Proof of sufficiency. Let $k=a(T)=d(T)$ be finite. Then ([6], Theorem 5.41-G) $T$ is completely reduced by the pair of closed complemented subspaces $R\left(T^{k}\right)$ and $N\left(T^{k}\right)$ of $X$ and

$$
X=R\left(T^{k}\right) \oplus N\left(T^{k}\right)
$$

Let $P$ be the projection from $X$ onto $R\left(T^{k}\right)$ along $N\left(T^{k}\right)$. Then

$$
P T^{k}=T^{k} P
$$

For each $x$ in $X, x$ can be written as $x=y+z$ where $y \in R\left(T^{k}\right)$ and $z \in N\left(T^{k}\right)$.

$$
\begin{aligned}
& T^{k} P x=T^{k} p(y+z)=T^{k} P y=T^{k} y \\
& P T^{k} x=P T^{k}(y+z)=P T^{k} y=T^{k} y .
\end{aligned}
$$

Since $N\left(T^{k}\right)=N\left(T^{n}\right)$ and $R\left(T^{k}\right)=R\left(T^{n}\right)$ for all $n \geqq k$, we have $X=$ $R\left(T^{n}\right) \oplus N\left(T^{n}\right)$ for all $n \geqq k$. This implies

$$
P T^{n}=T^{n} P \quad \text { for all } n \geqq k \text {. }
$$

$$
P T=T P \text {. }
$$

From (1), we have

$$
(T P) T^{k}=T^{k+1} P=(P T) T^{k}
$$

Thus, $P$ and $T$ commute on $R\left(T^{k}\right)$. Again, for each $x=y+z$ in $X$,

$$
P T x=P T(y+z)=P T y=T P y=T P x .
$$

Therefore $P T=T P$ on $X$.

(3) Define $Q=T R\left(T^{k}\right)$. $Q$ is a closed operator follows from the fact that $Q$ is bounded with closed domain. To show $Q$ has a bounded inverse on $R\left(T^{k}\right)$ we need only to prove that $Q$ maps $R\left(T^{k}\right)$ in a one one manner onto itself. Because $T$ maps $R\left(T^{k}\right)$ onto itself, so does $Q$. If $Q x=0$ with $x \in R\left(T^{k}\right)$ then

$$
0=Q x=Q T^{k} y=T^{k+1} y \quad \text { for some } \quad y \in R\left(T^{k}\right) .
$$


This implies $y N\left(T^{k+1}\right)=N\left(T^{k}\right)$, thus $x=T^{k} y=0$. We define

$$
D=Q^{-1} P
$$

(4) Now, we must show that $D$, defined as above, is a Drazin inverse of $T$, which is unique by ([2], Theorem 1). For every $x=y+z$ in $X$ with $y \in R\left(T^{k}\right)$ and $z \in N\left(T^{k}\right)$ then

$$
\begin{aligned}
& T D x=T Q^{-1} P(y+z)=T Q^{-1} P y=y \\
& D T x=Q^{-1} P T(y+z)=Q^{-1} T P(y+z)=Q^{-1} T y=y,
\end{aligned}
$$

so that $D T=T D$.

$$
D^{2} T x=Q^{-1} P T Q^{-1} P(y+z)=Q^{-1} P^{2} x=D x .
$$

Thus, $D=T D^{2}$.

Finally, $(T D)^{2}=T D T D=T D=P$. Hence $I-T D$ is a projection from $X$ onto $N\left(T^{k}\right)$ along $R\left(T^{k}\right)$. For any $x$ in $X$

$$
(I-T D) x \quad N\left(T^{k}\right)
$$

This implies $T^{k}(I-T D) x=0$ and then we have

$$
T^{k}=T^{k+1} D
$$

(5) It remains only to show that $k$ is the smallest positive integer such that $T^{k}=T^{k+1} D$. Suppose there is a positive integer $m<k$ such that

$$
T^{m}=T^{m+1} D
$$

then

$$
T^{m}(I-T D) x=0 \quad \forall x \in X,
$$

hence $(I-T D) x \in N\left(T^{m}\right)$. But $(I-D) x \in N\left(T^{k}\right)$, this contradicts the hypothesis that $k$ is the smallest common value of $a(T)$ and $d(T)$.

Proof of necessity. In Theorem 3 we have proved that if $D$ is the Drazin inverse of $T$ with index $k$ then $T^{2} D$ is a commuting generalized inverse of $D$ and $X=R(D) \oplus N(D)$. The proof will be complete if we can show that $R(D)=R\left(T^{k}\right)$ and $N(D)=N\left(T^{k}\right)$.

If $y \in R\left(T^{k}\right)$ then there is some $x \in X$ such that 


$$
y=T^{k} x=T^{k+1} D x=D T^{k+1} x \in R(D) .
$$

Conversely, if $y \in R(D)$ then there is some $x \in X$ such that

$$
y=D x=T D^{2} x=T^{2} D^{3} x=\cdots=T^{k} D^{k+1} x \in R\left(T^{k}\right) .
$$

This shows that $R(D)=R\left(T^{k}\right)$. Similarly, we can show that $N(D)=$ $N\left(T^{k}\right)$. Conclusion is that

$$
X=R(D) \oplus N(D)=R\left(T^{k}\right) \oplus N\left(T^{k}\right)
$$

This implies $T^{k}(I-T D) x=0$ and then we have

$$
T^{k}=T^{k+1} D
$$

(6) It remains only to prove that $k$ is the smallest positive integer such that $T^{k}=T^{k+1} D$. Suppose there is a positive integer $m<k$ such that

$$
T^{m}=T^{m+1} D
$$

then

$$
T^{m}(I-T D) x=0 \quad x \in X,
$$

hence $(I-T D) x \in N\left(T^{m}\right)$. But $(I-T D) x \in N\left(T^{k}\right)$, which contradicts the hypothesis that $k$ is the smallest common value of $a(T)$ and $d(T)$.

The proof of the necessary part is included in Theorem 1.

The operator $T$ can be written as

$$
T=T p+T(I-p)
$$

since $T$ and $p$ commute, then for each $x \in X$

$$
T(I-p)^{k} x=T^{k}(I-p) x=0 .
$$

This shows that $T(I-p)$ is nilpotent of order $k$. As mentioned earlier $T^{2} D=T P$ is a commuting generalized inverse of $D$, so that $T P$ has index 0 or 1 (it is zero when $T$ is invertible). The following theorem is proved by Greville ([4], Theorem 9.3) in finite dimensional space. It can be extended to the general case without changing the proof. We merely state: 
THEOREM 5. The decomposition (*) is the only decomposition of $T$ of the form

$$
T=A+B
$$

where $A$ has index 0 or $1, B$ is nilpotent of order $k$ and $A B=B A=0$.

Acknowledgement. The author takes pleasure in thanking Dr. S. R. Caradus for his valuable comments on this paper.

\section{REFERENCES}

1. S. R. Caradus, Generalized Fredholm Operators, to be published.

2. M. P. Drazin, Pseudo-inverse in associative rings and semigroups, Amer. Math. Monthly, 65 (1958), 506-514.

3. S. Goldberg, Unbounded Linear Operators, McGraw-Hill, N.Y., 1966.

4. T. N. E. Greville, Spectral Generalized Inverse of Square Matrices, MRC Technical Summary Report No. 823, Math. Research Center, U.S. Army, University of Wisconsin, Madison.

5. C. R. Rao, and S. K. Mitra, The Generalized Inverse of Matrices and its Applications, Wiley, N.Y., 1971.

6. A. E. Taylor, Functional Analysis, John Wiley and Sons, N.Y., 1967.

Received December 4, 1973.

QUeEn'S University, Kingston, OnTARIO 


\section{PACIFIC JOURNAL OF MATHEMATICS \\ EDITORS}

RICHARD ARENS (Managing Editor)

University of California

Los Angeles, CA 90024

\section{R. A. Beaumont \\ University of Washington \\ Seattle, WA 98105}

C. C. MOORE

University of California

Berkeley, CA 94720

\section{J. DUGUNDJI}

Department of Mathematics

University of Southern California

Los Angeles, CA 90007

R. FINN AND J. MILGRAM

Stanford University

Stanford, CA 94305

\section{ASSOCIATE EDITORS}

\section{E. F. BECKENBACH}

B. H. NeUmanN

F. WOLF

K. YoSHIDA

\section{SUPPORTING INSTITUTIONS}

\author{
UNIVERSITY OF BRITISH COLUMBIA \\ CALIFORNIA INSTITUTE OF TECHNOLOGY \\ UNIVERSITY OF CALIFORNIA \\ MONTANA STATE UNIVERSITY \\ UNIVERSITY OF NEVADA \\ NEW MEXICO STATE UNIVERSITY \\ OREGON STATE UNIVERSITY \\ UNIVERSITY OF OREGON \\ OSAKA UNIVERSITY
}

\author{
UNIVERSITY OF SOUTHERN CALIFORNIA \\ STANFORD UNIVERSITY \\ UNIVERSITY OF HAWAII \\ UNIVERSITY OF TOKYO \\ UNIVERSITY OF UTAH \\ WASHINGTON STATE UNIVERSITY \\ UNIVERSITY OF WASHINGTON \\ AMERICAN MATHEMATICAL SOCIETY
}

The Supporting Institutions listed above contribute to the cost of publication of this Journal, but they are not owners or publishers and have no responsibility for its contents or policies.

Mathematical papers intended for publication in the Pacific Journal of Mathematics should be in typed form or offset-reproduced (not dittoed), double spaced with large margins. Underline Greek letters in red, German in green, and script in blue. The first paragraph or two must be capable of being used separately as a synopsis of the entire paper. Items of the bibliography should not be cited there unless absolutely necessary, in which case they must be identified by author and Journal, rather than by item number. Manuscripts, in duplicate, may be sent to any one of the four editors. Please classify according to the scheme of Math. Reviews, Index to Vol. 39. All other communications should be addressed to the managing editor, or Elaine Barth, University of California, Los Angeles, California, 90024.

100 reprints are provided free for each article, only if page charges have been substantially paid. Additional copies may be obtained at cost in multiples of 50 .

The Pacific Journal of Mathematics is issued monthly as of January 1966. Regular subscription rate: $\$ 72.00$ a year (6 Vols., 12 issues). Special rate: $\$ 36.00$ a year to individual members of supporting institutions.

Subscriptions, orders for back numbers, and changes of address should be sent to Pacific Journal of Mathematics, 103 Highland Boulevard, Berkeley, California, 94708.

PUBLISHED BY PACIFIC JOURNAL OF MATHEMATICS, A NON-PROFIT CORPORATION

Printed at Jerusalem Academic Press, POB 2390, Jerusalem, Israel.

Copyright (C) 1977 Pacific Journal of Mathematics All Rights Reserved 


\section{Pacific Journal of Mathematics \\ Vol. 70, No. $2 \quad$ October, 1977}

B. Arazi, A generalization of the Chinese remainder theorem ........... 289

Thomas E. Armstrong, Polyhedrality of infinite dimensional cubes .... . . . 297

Yoav Benyamini, Mary Ellen Rudin and Michael L. Wage, Continuous

images of weakly compact subsets of Banach spaces ............ 309

John Thomas Burns, Curvature functions on Lorentz 2-manifolds ......... 325

Dennis F. De Riggi and Nelson Groh Markley, Shear distality and equicontinuity .................................. 337

Claes Fernström, Rational approximation and the growth of analytic

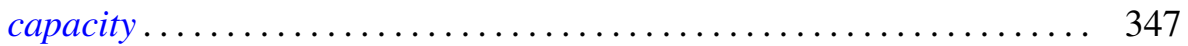

Pál Fischer, On some new generalizations of Shannon's inequality....... 351

Che-Kao Fong, Quasi-affine transforms of subnormal operators ......... 361

Stanley P. Gudder and W. Scruggs, Unbounded representations of

*-algebras........................................ 369

Chen F. King, A note on Drazin inverses .................... 383

Ronald Fred Levy, Countable spaces without points of first countability . . . 391

Eva Lowen-Colebunders, Completeness properties for convergence

spaces ......................................... 401

Calvin Cooper Moore, Square integrable primary representations ....... 413

Stanisław G. Mrówka and Jung-Hsien Tsai, On preservation of

E-compactness ................................ 429

Yoshiomi Nakagami, Essential spectrum $\Gamma(\beta)$ of a dual action on a von

Neumann algebra ................................ 437

L. Alayne Parson, Normal congruence subgroups of the Hecke groups

$G\left(2^{(1 / 2)}\right)$ and $G\left(3^{(1 / 2)}\right)$...

Louis Jackson Ratliff, Jr., On the prime divisors of zero in form rings . . . . 489

Caroline Series, Ergodic actions of product groups .................. 519

Robert O. Stanton, Infinite decomposition bases..................... 549

David A. Stegenga, Sums of invariant subspaces .................. 567 